\title{
Bridging Home and Host Country: Educational Predispositions of Chinese and Indian Recent Immigrant Families
}

\author{
June A. Gordon \\ University of California, Santa Cruz \\ U. S. A. \\ Xiangyan Liu \\ University of California, Santa Cruz \\ U.S. A.
}

\begin{abstract}
This research focuses on the predispositions that recent Chinese and Indian immigrant families bring with them to the United States and how these are reinforced by the communities in which they locate. The findings draw from 144 interviews in California. Three themes dominate: positioning through schooling, transnational family, and extended community and education. Our perspective joins Asian diaspora studies with cultural capital and social structural theories, enabling a more nuanced understanding of ways in which schooling in the home country informs how children are positioned in the American schooling system.
\end{abstract}

\section{KEYWORDS: Chinese-American, Indian-American, immigrant family, Asian} diaspora, cultural capital

Theoretical Framework

Methodology

Findings

Discussion

Conclusion

References

In a public kindergarten class in a city of California's Silicon Valley, there are 28 five-year old students: 27 of them are Asian; one of them is not. Twenty-seven of them operate at a third grade level; one of them does not. Twenty-seven have English as their second language; one has English as his native language. The teacher claims to have to constantly adapt to the needs of the one child who cannot keep up, who is acting like and learning like a kindergartener. He is White; the others, 17 who are Indian and 10 Chinese, need no assistance. When a "more progressive curriculum," which supposedly attends to a child's creative 
instincts, was offered, parents rebelled, asking for more homework, with children claiming to prefer tests to demonstrate their knowledge. The teacher and others like her are challenged daily to create a curriculum suited to the needs of students who have already been engaged in some form of preschool or supplemental learning long before kindergarten.

Per the 2010 census, the United States has the largest number of immigrants in the world, at more than 38 million; about one quarter of all youth are of immigrant origin (Suárez-Orozco, Darbes, Dias, \& Sutin, 2011). From 2000 to 2010, the population of Hispanic and Asian children grew by 5.5 million while the number of White children declined by 4.3 million (Frey, 2011). In 2013 Mexico was overtaken by both China and India as the biggest source of new migrants. But perhaps the most pronounced change lies not with demographics but with economics. Most of these newcomers are younger, better educated, and more transnational in their world view than their forbearers (Jiménez \& Horowitz, 2013). Around one third of 1.1 million foreign students are Chinese, with $70 \%$ of $\mathrm{H}-1 \mathrm{~B}$ visas going to Indians in high skilled jobs ("The Future's Asian," June 2015). According to the U.S. Department of State, the H-1B visa is for workers in an occupation that requires highly specialized knowledge. While this transformation is being felt across the country, it is clearly observed in California where as of 2010, Asians made up 13\% of the state's population, an increase of more than a million people in 10 years, from 3.7 million in 2000 to 4.9 million in 2010 (U.S. Census 2008-2012).

One of the results of this demographic shift is the marked increase in expectations placed on educators to respond to the demands of parents who, having experienced a different form of schooling in their home country, are redefining what education means in the United States and how it should be performed. Middle- and upper-middle-class non-Asian families, who once viewed their children as academically talented, have left "good" school districts either due to their desire for a more balanced approach to education or an awareness that their child cannot compete with many recent and affluent immigrants from China and India. This has given a new meaning to the term "White flight" (Hwang, 2005).

While immigrant education is often discussed in the literature (Gibson \& Ogbu, 1991; Rong \& Preissle, 2009; Rumbaut \& Cornelius, 1995) with some focus on those arriving from Asia (Lee, 2005; Lee \& Zhou, 2004; Louie, 2001), as well as the forces that shaped the model minority myth (Lee, 1996; Nakayama, 1988), little has been written on the ways in which educational attitudes and predispositions of Asian immigrant families are originating in their home country rather than being created upon arrival in the United States either as a reaction to life in America or as a result of migration. This paper attempts to complicate the existing picture of immigration by showing the interaction between home and host country in order to explore how recent Chinese and Indian immigrant families' predispositions towards schooling have been transferred to the United States. Two questions are addressed: 
1. What are these predispositions defined by the Chinese and Indian immigrant families?

2. How do they function and guide Chinese and Indian immigrant families in their educational choices once in the United States?

To explore these questions, it is essential to understand what schooling looks like in the home country and what education means for these immigrants, as well as how parents and community participate in their child/ren's schooling.

\section{Theoretical Framework}

This study is framed with three theoretical perspectives focusing on (a) home country context and education of minorities in the United States, (b) cultural and structural explanations on Asian immigrant education, and (c) intersection of diaspora and Asian immigrant education.

First, scholars struggle to find answers as to how and why members of a particular group understand and interpret their world, leading to predispositions and behavior that partly determine their schooling experiences and performance. History is viewed as an analytical unit that deepens our understanding of sociocultural dynamics on children's academic performance, including the folk theory of "making it" that reinforces beliefs from the home country that doing hard work, following the rules, and acquiring an education will increase the chances of success in the U.S. society (Ogbu \& Simons, 1998). As noted by Greenfield (1994), when people move to new locations, they bring with them "cultural scripts" that influence their adaptation, including their attitudes towards schooling. Schneider, Hieshima, Lee, and Plank (1994) extend Greenfield's transnational explanation in noting that the value a group places on education is historically determined and interfaces with the group's socioeconomic position in the host society. These points leave us with a few questions. How are cultural models and cultural scripts altered and/or transferred to the host country? How do they impact the way in which education is performed in the host country?

Second, cultural and structural perspectives have both been used as frameworks to explain the academic achievements of Asian Americans or Asian immigrants (Kaufman, 2004; Louie, 2001; Zhou \& Kim, 2006). This paper does not focus on academic achievement, but rather on how attitudes and expectations shaped through schooling system in the home country influence educational decisions in the host country. Bourdieu's theory of cultural capital assists with understanding how parental educational expectations influence academic attainment and achievement, while the social structural theory developed by Steinberg suggests that gender, socioeconomic status, urbanicity, family composition, immigrant status, and parent education play a decisive role (Pearce, 2006). With regard to education of recent Chinese and Indian immigrants, the cultural explanation emphasizes the cultural resources of parents 
while the structural explanation stresses the economic demand and the opportunity structure in shaping their education.

Third, while a proliferation of diaspora studies has been produced across the humanities and social sciences since the 1990s, the discussion seldom reaches into education (Knott \& McLaughlin, 2010). Lukose (2007) also wonders about the absence of a framework of diaspora from the anthropological literature on immigration and education in the United States. Few scholars discuss the context of Asia in understanding Asian immigrant families. Most studies view the United States as the destination of a one-way trajectory of immigration, something that we found not to be true among our informants who tended to be transnational in their orientation. In this paper we argue for an intersection of diaspora studies (Cohen, 1997, 2008; Hall, 1990) with immigrant education (Suarez-Orozco, et al., 2011) to provide an alternative and more useful framework for examining the education of immigrants. Diasporic studies as a theoretical framework provides an approach to understanding ways in which immigrant communities build upon one another and evolve as varying attitudes and expectations are brought in by more recent arrivals. By including Asian diaspora studies, our perspective shifts from one bounded by the notion of nation-state to one that extends and bridges multiple worlds (Shukla, 2003; Wang, 1995). This in turn allows us to reframe our analysis of education as we come to see it shaped by and a part of a transnational migration experience.

\section{Methodology}

The work offered in this paper is part of a larger research project that one of the authors has been engaged in for the last 10 years. During this period over 700 interviews have been gathered from individuals who are either first, second, or third generation immigrants from 10 specific countries/regions in Asia. The 10 countries include Japan, Korea, China, Hong Kong, Taiwan, India, Vietnam, Cambodia, Laos, and the Philippines, sources that historically have had the greatest flow of immigrants to the United States from Asia.

However, for this article the analysis and discussion of the findings will be limited to interviews with members of recent Chinese and Indian immigrant families, since these two groups have the largest number of recent immigrants to the San Francisco Bay Area, the location of the study. For Chinese we are including for this article immigrants from Taiwan and Hong Kong as well as the People's Republic of China. Indians could be descendants of people who were living in either what is now called Pakistan or in contemporary India.

The methodological tool used in this project is Critical Dialogic Inquiry (Gordon, 2002), a form of iterative ethnographic research whereby the interviewers not only receive responses to their questions but also stimulate inquiry in the interviewee who often, not having a full understanding of the issues that undergird the research question, seeks answers and/or further discussion 
with family and friends to fill in missing knowledge. The result is transformative for all involved, particularly because the research asks that the interviewee reflect on how the attitudes, expectations, and traditions of the home country affected their educational experiences in the United States or that of their children.

One hundred and forty-four interviews, 90 from Chinese and 54 from Indian informants, were conducted over a three-year span. Interviewers were college-age students who served as assistants, conducting face-to-face, in-depth interviews with members of recent immigrant families from China and India. Each assistant was trained in ethnographic interviewing methods and given potential interview questions and prompts to guide the discussion of the research question. The interviewee families had their origins in a range of locations across China and India. A few of the assistants knew one of their interviewees prior to the interview but most interviewed strangers. Most interviewees claimed to have never thought about or discussed these issues before. Those assistants who had prior knowledge claimed that the interview provided them with a totally new and different awareness of their interviewee. As the interviews were completed, they were read and coded first by the assistants and then separately by both authors based on the Pattern Coding Method offered by Saldaña (2009). A list of dominant and redundant themes emerged which were then checked against findings from prior years of research by the authors. The themes were further informed by data drawn from surveys, self-portraits, personal reflections, and informal conversations with both the interviewers and the interviewees.

\section{Findings}

Acknowledging the variation in themes within and between the responses of Chinese and Indian interviewees, we have selected for this article three that we felt could be of value in a substantive discussion on the issue of home/host country transference. These include positioning through schooling, transnational families, and extended community support and education. Quotes are used to clarify the nuanced nature of this work. While we hope the findings assist in understanding ways in which attitudes towards education have been shaped by forms of schooling in the home country, we are aware that this is not a representative sample as the voices provided are mostly, though not entirely, of college-age individuals who have succeeded in obtaining entrance to a major public university. However, we also want to state that these findings are not unique to the Bay Area in California; similar situations are replicated throughout the United States.

\section{Positioning through Schooling}

Most Chinese and Indian parents represented in this study, regardless of socioeconomic status, sought out "the best" schools for their children rather than relying on local neighborhood offerings. These "top" schools often were the ones 
with not only the highest API (Academic Performance Index) scores but also the ones with the largest number of "Asian" students. As a result, we often heard of schools whose identities had been radically altered over the last 20 years from "neighborhood" school to "top" school simply by attracting affluent Chinese and Indian students, even when the teachers and their pedagogy remained the same. To gain access to these schools, parents contrived ingenious ways to position their child/ren, often at the expense of the overall welfare of the family as a unit, even if this meant moving two or three times, or illegally using someone else's address to claim residency. The cost was viewed as worth the effort, as noted by Mirai:

My parents would drive me to my uncle's house 45 minutes away in order to attend the high school there. I used to show up at his house at 6 A.M. and then walked to school. I went there because my parents said it was a good school even though we lived 5 minutes from a high school. (1.5generation Indian)

For some the disruption came at the end of each school level, as recounted here: "Our family moved several times during my childhood in order to get into the best elementary, middle and high schools, each in a different housing zone of the city" (1.5-generation Chinese).

Urban schools with high "diversity," usually a term used to mean predominantly African American and Latino youth, tend not to be attractive to most Chinese and Indian parents. In part, this is a class issue. Many new immigrants from these two countries are from middle- and upper middle-class educated families and prefer to associate with those who not only share their social standing but also their cultural view on how one should perform in school; this is true even within the same "ethnic" group. But it is also a racial issue. Most of these immigrants see themselves as having a common identity based on the majority population of their home country. They do not see themselves within the American image of "minority" in part because they come from cultures where they are in the majority and because most settle in ethnic enclaves once they arrive.

My father settled in Sunnyvale, California, where there is a large population of Asian Indians. Then later he moved our family to Fremont for better education opportunities. It also has a huge Asian Indian population. I never felt like I was a minority (Second generation Indian).

The issue of social standing is complex and can be based on either the position one held in the home country or the one acquired upon immigration. We found three common trends related to this issue throughout the interviews. First, parents with strong educational and economic status back home faced downward mobility once in the United States due to the inability to transfer their credentials. Yet regardless they retained the awareness of their prior status and strove to insure that their children would be positioned appropriately to regain it. The second trend involved providing a relatively smooth transition between one's status in the home country and the host country; usually these were the $\mathrm{H}-1 \mathrm{~B}$ 
visa holders or those who could become recertified in the United States or return to college for advanced training to obtain professional employment. The third trend was composed of individuals who arrived without much economic or cultural capital, who had struggled with their education back home, or who were escaping family or political crisis. Often these individuals were willing to accept lower-level jobs. However, because they were ethnically part of one of these two recent dominant immigrant communities that were seen as both educationally and economically powerful, there was a tendency to attempt to emulate the larger Chinese or Indian community's way of doing things, including the degree of pressure placed on youth to match up to their ethnic peers. The goal for most of these immigrants, regardless of social standing or economic class, is to acquire what they perceive as the best education for their child/ren in order to access a name brand university or college.

To this day, my parents don't really seem to care about the experiences that I get...they only seem to see the name [of the school]... They are still pushing me after two years to transfer out of this school and into Stanford or MIT. ( $2^{\text {nd }}$ generation Taiwanese)

Credentials from elite brand-name institutions are seen as not only providing increased employment options and, hence, money, but also status within the community. Seldom were issues of social justice or the value of liberal arts education mentioned. "Education for equity" is not foremost in the minds of these Chinese or Indian parents. While elite institutions also exist in the home country, they are few in number and most do not hold the same status as a degree from abroad. Demand for access to U.S. schools that fit the category of "most highly ranked" in the eyes of these immigrants exceeds supply, resulting in families not only feeling disappointment in their move to the United States but also in their children if they are unable to gain entrance.

\section{Transnational Family}

The decision to become a transnational family is not an easy one and takes many forms, as noted by a range of scholars (Finch \& Kim, 2012; Gardner, 2012; Orellana, Thorne, Chee, \& Lam, 2001; Yeoh, Huang, \& Lam, 2005). A transnational family is often viewed as a family where core members live in two or more nation-states but continue to share bonds of collective welfare and unity (Bryceson \& Vuorela, 2002). For Indians this usually meant the separation of the nuclear family from the extended, but the nuclear family arrives intact and remains close. For the Chinese, the scenario tended to be quite different as noted by Zhou (2009) and by Ma and Cartier (2003). The Chinese allow the fracturing of the nuclear family. The most common form results in the father continuing to work in China while the mother, after giving up her job, accompanies the child. However, other alternatives were often alluded to in the interviews, including sending a child alone, or having him/her "parachuted" into an area to live with a guardian who could be a relative or a stranger who accepts payment. 
One particular example that struck us was that of a Chinese mother from Beijing who arrived in 2013 with her middle-school-aged son with the specific purpose of enrolling him into the same school as was attended by famous Silicon Valley CEOs and/or their children. The husband remained in China with his job and sent money to support the endeavor. The rent for their exclusive 3-bedroom house was about $\$ 7,000$ per month. The family, desperate to live in this neighborhood, signed a year's contract at this rate, sight unseen, and paid the entire amount prior to moving in. When asked the rationale behind such a decision, the mother responded,

A few years ago, a friend told us about this neighborhood and visited the school. It is the only public middle school in the area, all the rest are private. I thought if my son could score high enough on his tests, he could then go on to the same elite private high school where I heard Steve Jobs sent his kid. (First generation from China)

While this interview might seem like an extreme example, the mindset is not very different from what we found overall. In a few cases it was the mother that remained behind as the bread winner, as seen here:

My father and sister immigrated to the U.S. in 1998, while my mother stayed behind to continue her career in Taiwan. This didn't seem like such a big deal to me back then because I always assumed that my mother would follow or that we would eventually go back. (1.5-generation Chinese)

Beyond the direct movement from home to host country, several families had moved multiple times not just within California but across the world to position their children and their futures creating a transnational awareness of their identity and sense of belonging. One example was Jen, who was born in Taiwan but attended kindergarten in Canada. At age of 8 , her family moved back to Taiwan. At first she attended a local school but, unable to make the adjustment, moved to the Taipei American International School because her parents realized that she would not be able to compete well in the Chinese high school final exam. Without success in this exam, entrance to a Chinese university is impossible. As a result, Jen applied to an American university and fortunately was accepted to Boston University.

Similar to Jen, Chris shared a more complex transnational experience:

My family originally came from Bombay, then we moved to Dubai. A few years later, my parents decided to move us to Vancouver where the schools were supposed to be "interesting". But then my parents found out that schools in the U.S. were even better, so we all moved again to Southern California. (First generation from India)

But transnational families are not just about educational positioning; in the cases of both India and China, transnationalism was a way of life, a mindset, for most of our interviewees. Due to their high economic status they were able to travel back and forth to the home country on a regular basis. This was true not 
only for their parents' jobs but also for visits to extended families, usually in the summer. Some of them believe that the transnational experience will make them stand out with the skills gained in different cultures. Maintaining a transnational identity was also reinforced daily through electronic communication on numerous levels, enabling many interviewees to view their education in the United States as much a preparation to work in the home country as in the United States, if not on an even wider international scale.

In contrast to many other immigrant communities, such as those from Mexico or the Philippines, money flowed as much into the host country as out of it. These "reverse remittances" enabled middle- and upper middle-class families to take the risk of coming to the United States with the financial support from the home country. This is not the typical traditional immigrant story. Ironically, in part what has created this transnationalism is not only economic and educational capital but also British colonial history. More than a few of the Indian interviewees had parents who had come from a range of African countries including Kenya, Tanzania, and South Africa, or had family living in the United Kingdom. Chinese informants came from Singapore, Hong Kong, and Canada. One 1.5-generation Indian interviewee claimed, "I would be able to find a person I am somehow related to anywhere in the world."

It is essential to remember that those who are able to live transnational lives are in the minority in their home countries. Nevertheless, what it means to be "few in numbers" comes from the two most populous nations in the world; hence, the impact is considerable. Unless we understand the cultural, social, and economic capital that the transnational families bring with them and how this functions differently from that of other or prior immigrants, as well as longstanding Americans, we will misinterpret the process and the product.

\section{Extended Community Support and Education}

Most Chinese and Indian parents do not see public schooling as sufficient to educate their children to an acceptable level. Having gone to school in countries where supplementary education is the norm in order not only to keep up with the standardized curriculum but to succeed on the nationalized exams, parents assume that such would naturally be the case in the United States. The predisposition to send one's child/ren off for additional classes might seem excessive, but for most of the interviewees it was seen as a sign of not only parental involvement but also parental care.

However, the way in which extended education plays out in these two communities is a bit different. Indian families tend to take more of the responsibility for tutoring their children directly. As noted in these two 1.5generation Indian interviewees:

"My mother tutored me every night. And when she couldn't, my sister was expected to take over. She used workbooks and followed a strict schedule designed by my mother." 
"My parents never forced me into tutoring or summer school but education had to be my main focus. I was expected to have perfect grades, perfect study habits, perfect handwriting, and perfect posture."

In comparison, Chinese tend to rely on entrepreneurial community structures to provide services which reinforce the pressure they already experience at home. These programs and stores are often replicas of what exists in the home country, ranging from bookshops featuring materials for parents/mothers that complement their children's coursework to actual copies of tests that can be repeatedly administered to insure top scores.

Students in Hong Kong really value supplementary school. So when my daughters started elementary school here in the U.S. I spent thousands of dollars to make sure they got afterschool tutoring and weekend classes. I wasn't just concerned about academics; I also enrolled them in martial arts classes to learn discipline, ballet for coordination, basketball for teamwork, and piano for creative expression. (First-generation from Hong Kong)

The difference between Chinese and Indian families might be due to the fact that many more Indian mothers in this study held college degrees, as did the grandparents. Because most of these women did not find commensurate work in the United States or opted not to work until later in life, they invested their talents in their child's education. While most Chinese parents in this research were also educated, the grandparents tended not to be, in part due to the Cultural Revolution and in part to the economic push in the 1980s which prioritized money over education. While Indian youth also attended supplementary classes, including Bengali school and SAT prep programs, the Chinese informants, as noted below, relied on ethnic businesses which often fueled parents' fear that without such services their child would fall behind, "My cousins received tutors since the $3^{\text {rd }}$ grade, this is the norm. If one doesn't have a tutor, it means that the student is failing." The cost of such programs was not a major concern for our interviewees as shared by the father from Hong Kong in the previous quote.

The social importance of these programs for parents should also not be underestimated. Many are the stories of parents who push their child into extracurricular programs in order to have contact with other adults struggling to figure out the U.S. system or, more often than not, to compare and brag about the successes of their child/ren. In these settings parents swap stories of food and vitamins that bolster a child's attention span, increase concentration, and strengthen sustainability. The appreciation of community support is seen in the voice of this young interviewee:

Coming from China my mom and I were both strangers to extracurricular activities. She had to learn from what others in the community were doing to figure out that this was something that American society valued. Back in China the focus was on academics; there is little time for anything else. (1.5-generation from China) 
While extracurricular education on weekends and afterschool might increase educational and social capital through training and association with peers who share and enforce common norms, it also serves as a way to monitor the behavior and movement of young people. If a child's free time is circumscribed to insure attendance at various classes, supplementary education can take on a more demanding form.

On Saturdays, I never got to sleep in or watch cartoons. Early in the morning, I would go off to piano class, and then straight to tutoring. That would be my entire Saturday.... It was a way for me to be ahead of the class, to be ready for any test that I might have to take. I never questioned my parents or why they were so strict. (1.5-generation from Hong Kong)

It is little wonder that time on task results in higher academic performance. This may have less to do with intelligence or ability than focus, discipline, and perseverance reinforced by the norms of parents, community, and peers, along with the expectation that every child should attempt to be "the best."

My brother and I knew that we had to hold ourselves to the highest educational standard possible, meaning straight A's and all honors and A.P. courses throughout our education because all of my cousins had bachelors to a PhD. (Second generation Indian)

But the hard work was also based on fear of dishonoring the family. Jana shares, "Schoolwork always comes before friends. I try to do my best in school in order to avoid bringing shame on my family." Yet it is not just the family that applies the standards and pressure, Sometimes even when parents are not strict with their children, the community and peer group step in as the enforcer of expectations. One Indian informant shared, "The community here places huge pressure on us to succeed which at times is toxic." Clearly, potential conflict arises when teachers and schools must respond to the needs of these students and parents along with those who may share a different view on children, education, and life.

\section{Discussion}

What it means to be educated is not a universal concept. Generations of Americans have prided themselves, for good or for ill, on the belief that the best education is one that balances the social with the academic in an attempt to combine democratic equality, social efficiency, and social mobility (Labaree, 1997). However, the findings from this research continued to demonstrate that many recent immigrants from China and India did not share such belief structures as the underlining premises of education. To better understand these alternative frames of reference we looked at three theoretical areas: home country context, cultural and social explanations, and diaspora studies.

As discussed earlier, newly arriving Chinese and Indian immigrant parents' frame of reference is situated in the "home" country, whether it be their 
own experience or a faded image from generations passed but reified in an ethnic enclave. They bring with them into their role as parents and guardians mentalities of what it means to be educated, what it looks like, and who is best able to perform the function of educating their youth. In contrast to the view that striving for a competitive edge in education is a product of the immigrant experience and is often attributed to discrimination or an attempt to prove oneself better than those in the host country, we argue that it is rather based on educational experiences back home that are transferred to the host country. When these cultural expectations are then reinforced by the immigrant community sanctions and supported by privatized educational institutions with a focus on academic performance, a climate is established that predisposes children to succeed or, if not, to risk the social ostracization of not being "as good as" another child.

The reason often given for this situation is that Asians value education more than other groups (Nakanishi \& Nishida, 1994). This is a fallacy; the majority of parents, regardless of ethnic background, value education (SuarezOrozco, Suárez-Orozco, \& Todorova 2008). Another reason given is that immigrants from Asia have struggled with survival. This is also erroneous; most immigrants have struggled and sacrificed, many with the goal of providing their children with better educational opportunities (Portes \& Rumbaut, 2001). Others say it has to do with a Confucian background $(\mathrm{Ho}, 1986)$. But Confucianism is largely a form of social order to insure the stability of the state and does not dominate all Asian cultures. Another reason given is the centrality of the family. We would argue that the family is important to the majority of people and, in contrast to other cultures, it is notable that many contemporary Asian families in this study willingly fractured their families in order to position their children in institutions of global status. What tends not to enter into this equation is the established mindset of those immigrants from their home countries and how their worldview has been shaped by the economic, social, cultural, historical, and political contexts from which they left.

To better explore the complexity of educational perspectives offered by recent Chinese and Indian immigrants, we strongly suggest the use of a diasporic framework (Ma \& Cartier, 2003; Shukla, 2003; Toloyan; 1996, Van Hear, 1998), which captures the process of immigration not as an uprooted directional trajectory but rather as a complex space where people from a range of backgrounds come to forge their multiple identities while building new and varied communities in a transnational context. The diasporic and transnational framework enables a discussion on immigrant education that moves us beyond a nation-bounded view on immigration and, more importantly, to an understanding of how recent Chinese and Indian immigrant families' predispositions towards schooling have been shaped and transferred to the United States. 


\section{Conclusion}

This paper argues that educational expectations and attitudes towards what constitutes quality schooling in the United States are in large part shaped by the schooling experiences that Chinese and Indian immigrant parents have received in their home country as influenced by political, economic, and social factors. The findings, drawn from 144 interviews, are organized in three dominant themes: positioning through schooling, transnational family, and extended community support and education. Quotes offer examples of these themes. Our conceptual perspective joins Asian diaspora studies with cultural capital and social structural theories, enabling a more nuanced understanding of the ways in which schooling in the home country informs how children are positioned in the American schooling system.

We suggest that unless we understand these differences, as well as why Chinese and Indian students, in the aggregate, tend to outperform other students in U.S. schools, we will not be able to succeed in closing the achievement gap; nor will we be able to address the variation in quality of schooling being demanded from different sectors of the U.S. society. What is being asked for by many recent immigrants from China and India is often not compatible with what has been traditionally viewed as the essence of American education. A compromise must be reached given the incredible diversity represented in our schools. We cannot return to a time of segregation where the presumption suggests that some students are innately more capable than others. How American education will evolve and adjust to the influx of recent middle class immigrants from China and India is still an open question. No one should be absent from this conversation as it will affect us all. Those who have access to quality higher education and skills are those who will be best positioned to decide the future of this country and the world. Without a greater understanding of schooling in the home countries of our students and how their options have been shaped by political, social, and economic factors, we remain ignorant of the growing segregation that is occurring before our eyes.

\section{References}

Bryceson, D. F., \& Vuorela, U. (Eds.). (2002). The transnational family: New European frontiers and global networks. New York, NY: Berg.

Cohen, R. (1997). Diasporas, the nation-state and globalization. In G. Wang (Ed.), Global history and migrations (pp. 117-143). Boulder, CO: Westview Press.

Cohen, R. (2008). Global diaspora: An introduction (2nd ed.). London, UK: Routledge. 
Finch, J., \& Kim, S. K. (2012). Kirŏ gi families in the US: Transnational migration and education, Journal of Ethnic and Migration Studies, 38(3), 485-506. doi:10.1080/1369183X.2012.658548

Frey, W. H. (2011). America's diverse future: Initial glimpses at the U.S. child population from the 2010 Census. Washington, DC: Metropolitan Policy Program at Brookings Institution.

Gardner, K. (2012). Transnational migration and the study of children: An introduction. Journal of Ethnic and Migration Studies, 38(6), 889-912. doi:10.1080/1369183X.2012.677170

Gibson, M. A., \& Ogbu, J. U. (Eds.). (1991). Minority status and schooling: A comparative study of immigrant and involuntary minorities. New York, NY: Garland.

Gordon, J. A. (2002). Immigrants and education: Dialogic inquiry as pedagogy. Teaching Sociology, 30(3), 278-290.

Greenfield, P. (1994). Independence and interdependence as developmental scripts: Implications for theory, research, and practice. In P. Greenfield and R. Cocking (Eds.), Cross cultural roots of minority child development (pp. 1-42). London, UK: Taylor \& Francis.

Hall, S. (1990). Cultural identity and diaspora. In J. Rutherford (Ed.), Identity: Community, culture, difference (pp. 222-237). London, UK: Lawrence and Wishart.

Ho, D. Y. F. (1986). Chinese patterns of socialization: A critical review. In M.H. Bond (Ed.), The psychology of the Chinese people (pp.1-37). Oxford, UK: Oxford University Press.

Hwang, S. (2005, Nov). The new White flight: In Silicon Valley, two high schools with outstanding academic reputations are losing white students as Asian students move in. Why? The Wall Street Journal. Retrieved from http://online.wsj.com/article/SB113236377590902105.html

Jiménez, T. R., \& Horowitz, A. L. (2013). When White is just alright: How immigrants redefine achievement and reconfigure the ethnoracial hierarchy. American Sociological Review, 78(5), 849-871. doi: 10.1177/0003122413497012

Kaufman, J. (2004). The interplay between social and cultural determinants of school effort and success: An investigation of Chinese-immigrant and second-generation Chinese students' perceptions toward school. Social Science Quarterly, 858(5), 1275-1298.

Knott, K., \& McLaughlin, S. (2010). Diasporas: Concepts, intersections, identities. London, UK: Zed Books.

Labaree, D. F. (1997). Public goods, private goods: The American struggle over educational goals. American Educational Research Journal, 34(1), 39-81. 
Lee, S. J. (1996). Unraveling the "model minority" stereotype: Listening to Asian American youth. New York, NY: Teachers College Press.

Lee, S. J. (2005). Up against whiteness: Race, school, and immigrant youth. New York, NY: Teachers College Press.

Lee, J., \& Zhou, M. (2004). Asian American youth: Culture, identity, and ethnicity. New York, NY: Routledge.

Louie, V. S. (2001). Parents' aspirations and investment: The role of social class in the educational experiences of 1.5- and second-generation Chinese Americans. Harvard Educational Review, 71(3), 438-474.

Lukose, R. (2007). The difference that diaspora makes: Thinking through the anthropology of immigrant education in the United States. Anthropology \& Education Quarterly, 38(4), 405-418.

Ma, L. J. C., \& Cartier, C. L. (2003). The Chinese diaspora: Space, place, mobility, and identity. Lanham, MD: Rowman \& Littlefield.

Nakanishi, D. T., \& Nishida, T. Y. (1994). The Asian American educational experience: A sourcebook for teachers and students. New York, NY: Routledge.

Nakayama, T. K. (1988). "Model Minority" and the media: Discourse on Asian America. Journal of Communication Inquiry, 12(1), 65-73. doi: 10.1177/019685998801200106

Ogbu, J. U., \& Simons, H. D. (1998). Voluntary and involuntary minorities: A cultural-ecological theory of school performance with some implications for education. Anthropology \& Education Quarterly, 29(2), 155-188.

Orellana, M. F., Thorne, B., Chee, A. \& Lam, S. E. (2001). Transnational childhoods: The participation of children in processes of family migration. Social Problems, 48(4), 572-591.

Pearce, R. R. (2006). Effects of cultural and social structural factors on the achievement of White and Chinese American students at school transition points. American Educational Research Journal, 43(1), 75-101.

Portes, A., \& Rumbaut, R. G. (2001). Legacies: The story of the immigrant second generation. Berkeley, CA: University of California Press.

Rong, X. L., \& Preissle, J. (2009). Educating immigrant students in the 21st century: What educators need to know (2nd ed.). Thousand Oaks, CA: Corwin Press.

Rumbaut, R. G., \& Cornelius, W. A. (Eds.). (1995). California's immigrant children. San Diego, CA: University of California Press.

Saldaña, J. (2009). The coding manual for qualitative researchers. Thousand Oaks, CA: Sage.

Schneider, B., Hieshima, J. A., Lee, S., \& Plank, S. (1994). East-Asian academic success in the United States: Family, school, and community 
explanations. In P. M. Greenfield \& R. R. Cocking (Eds.), Cross-cultural roots of minority child development (pp. 323-350). Hillsdale, NJ: Lawrence Erlbaum.

Shukla, S. (2003). India abroad: Diasporic cultures of postwar America and Britain. Princeton, NJ: Princeton University Press.

Suárez-Orozco, C., Suárez-Orozco, M. M., \& Todorova, I. (2008). Learning a new land: Immigrant students in American society. Cambridge, MA: Belknap Press of Harvard University Press.

Suarez-Orozco, M.M., Darbes, T., Dias, S. I., \& Sutin, M. (2011). Migration and schooling. Annual Review of Anthropology, 40, 311-328.

The Future's Asian (2015, June 6). Economist, p. 20.

Tölölyan, K. (1996). Rethinking diaspora(s): Stateless power in the transnational movement. Diaspora, 5(1), 3-36.

U.S. Census Bureau. (2008-2012). Profile of ACS Demographic and Housing Estimates, DP05. [Data File]. 2008-2012 American Community Survey 5Year Estimates. Retrieved from http://factfinder2.census.gov

Van Hear, N. (1998). New diasporas: The mass exodus, dispersal and regrouping of migrant communities. London, UK: UCL Press.

Wang, L. C. (1995). The structure of dual domination: Toward a paradigm for the study of the Chinese diaspora in the United States. Amerasia Journal, 21(1\&2), 149-169.

Yeoh, B. S. A., Huang, S., \& Lam, T. (2005). Transnationalizing the "Asian" family: Imaginaries, intimacies and strategic intents. Global Networks, 5(4), 307-315.

Zhou, M., \& Kim, S. (2006). Community forces, social capital, and educational achievement: The case of supplementary education in the Chinese and Korean immigrant communities. Harvard Educational Review, 76(1), 1-29.

Zhou, M. (2009). Contemporary Chinese America: Immigration, ethnicity, and community transformation. Philadelphia, PA: Temple University Press.

\section{Author Contact}

June A. Gordon: jagordon@ucsc.edu

University of California, Santa Cruz: 1156 High St, Santa Cruz, CA 95064

Xiangyan Liu: liu-xiangyan@ hotmail.com

University of California, Santa Cruz: 1156 High St, Santa Cruz, CA 95064 